\title{
Estudio de caso de rabia humana transmitida por murciélago hematófago en Yucatán, México.
}

Caso Clínico

Salvador Gómez-Carro, Martín L. Ortiz-Alcaraz, Eusebio Jiménez-Ríos, Saúl De Los Santos-Briones, Enrique Marín-Pech.

Servicios de Salud de Yucatán, Mérida, Yucatán, México.

\section{RESUMEN.}

Introducción. En 1998 en Yucatán se registró el último caso de rabia humana transmitido por perro. En 2001 ocurrió el primer caso en una niña de 4 años transmitido por un animal silvestre, pero sin reportarse ningún caso en humanos por agresión directa de vampiro.

Caso clínico epidemiológico. Se estudió a una menor de 12 años fallecida por un síndrome febril y de encefalitis viral que se sospechó por virus rábico, aún sin el antecedente o evidencia de agresión por algún animal. Se obtuvo la cobertura de vacunación antirrábica de perros y gatos de la localidad afectada, realizando estudio de los contactos y de las condiciones de la vivienda y áreas aledañas.

Discusión. Se identificó como probable causa la mordedura inadvertida de un vampiro, facilitada por una vivienda precaria colindante a una cueva de quirópteros. El diagnóstico se confirmó postmortem por el Instituto Nacional de Referencia Epidemiológica reportando la variante antigénica V5 de murciélago hematófago. Se destaca la importancia de realizar acciones preventivas en la comunidad ante la sospecha del diagnóstico de rabia humana. Se concluye que es necesaria la vigilancia zoonótica colateral para detectar nichos de murciélagos hematófagos en localidades rurales. (Rev Biomed 2006; 17:118-122)

Palabras clave: Caso de rabia humana, murciélago hematófago, virus de la rabia.

\section{SUMMARY.}

Case study of human rabies transmitted by a hematophagous bat in Yucatan, Mexico.

Introduction. The last known case of human rabies in Yucatan transmitted by a dog was registered in 1998. In 2001 the first case transmitted by a wild animal was reported in a 4 year old girl. However, there had not previously been a case registered by vampire bats.

Epidemiologic clinical case. The results of the study done on the body of a 12 year old girl from the state of Yucatan showed she died from febrile syndrome and viral encephalitis. These symptoms are consistent with the rabies virus infection; however, there was no supporting report

Solicitud de sobretiros: M. en C. Salvador Gómez Carro, Calle 7-A No. 96-B por 22 y 22-A, Frac. Rinconada de Chuburná, C.P. 97200, Mérida, Yucatán, México. Correo electrónico: sgc@salud.gob.mx 
S Gómez-Carro, ML Ortiz-Alcaraz, E Jiménez-Ríos, S De Los Santos-Briones, E Marín-Pech.

or evidence of aggression by a domestic or wild animal. As a result, investigations were carried out to identify any indicators relating affected to: animal aggression, co-existence with domestic animals, anti-rabies vaccination in these domestic animals, recent human and animal contacts of the individual, and inspection of housing conditions and the surrounding area.

Discussion. A further epidemiologic study identified that an unexpected bite from a vampire bat was the probable cause of the infection. This conclusion was supported by the investigation which showed that her housing conditions were precarious, and the house was located next to a cave which is a common habitat for vampire bats. The diagnosis was confirmed post-mortem by The National Institute of Epidemiologic Reference which found the AgV5 rabies antigenic variant of a bat. In conclusion, we stress the importance of carrying out preventative measures to detect and keep a watch on colonies of vampire bats when there is a suspected diagnosis of rabies in a rural community. (Rev Biomed 2006; 17:118-122)

Key words: case of human rabies, vampire bats, rabies virus.

\section{INTRODUCCIÓN.}

La rabia humana es una zoonosis que afecta principalmente a la población que vive en condiciones de pobreza extrema, que convive con animales domésticos y que al igual que éstos pudiera exponerse a padecer la enfermedad en cualquiera de sus ciclos, urbano o silvestre (1).

La OMS señala que los países en desarrollo presentan más del $99 \%$ de las muertes por rabia humana y que esta zoonosis no ha sido puesta bajo control en la mayoría de los países afectados. En África y Asia se estiman hasta 55 mil defunciones anuales (2). En América Latina la tendencia de la enfermedad ha sido descendente desde que la OPS promovió la iniciativa de eliminar la rabia humana transmitida por perro para el año 2005. En efecto, de 1982 a 2003 los casos en humanos se redujeron de 355 a 35 y en los caninos de 15,686 a 1,131 casos (una reducción en ambos eventos mayor al 90\%). En más del 80\% de los casos la fuente de infección reportada fue el perro y en segundo lugar el murciélago. Para 2004 la región notificó 20 casos de rabia humana transmitida por perro, pero por arriba de esta cifra, un incremento de los casos transmitidos por animales silvestres (71), de los cuales más de la mitad (46) fueron por murciélago hematófago. Siendo Brasil, Colombia y Perú los países que presentaron los brotes más importantes de rabia humana (44 de los 46 casos) debidos a esa especie (3).

La OPS atribuye el éxito señalado a las campañas masivas de vacunación antirrábica canina y al tratamiento profiláctico oportuno realizado a personas expuestas. En América Latina se vacunan anualmente alrededor de 44 millones de perros y se atiende aproximadamente a 1 millón de personas en riesgo de contraer la enfermedad, de las cuales el 25\% reciben tratamiento postexposición. Para el diagnóstico y vigilancia más de 100 laboratorios nacionales y regionales integran la red para el diagnóstico de la rabia.

En México a partir de 1990, con el inicio de las Semanas Nacionales de Vacunación Antirrábica Canina se observa una tendencia descendente del padecimiento, de 69 casos notificados en humanos en 1990 a 4 casos en el 2000. En la casuística de la Secretaría de Salud se establece que del total de casos registrados en la década citada la fuente principal de infección fue el perro en el 87.3\% de los casos, el $16 \%$ el quiróptero y el resto otros animales silvestres. Del mismo periodo se tuvo una disminución del 92\%, de los casos de rabia canina, de 3,049 a 244 casos (4). De 2001 a 2004 se presentaron un total de 13 casos de rabia humana, y de éstos 3 fueron transmitidos por perro y 11 por especies silvestres no especificadas.

En Yucatán en 1998 se registró el último caso de rabia humana transmitido por perro; en 2001 el primero ocasionado por un animal silvestre (una agresión por zorrillo a una menor de 4 años,

\section{Revista Biomédica}




\section{Rabia humana transmitida por murciélago hematófago.}

positiva a la variante antigénica V3 de murciélago hematófago), pero sin haberse reportado hasta 2003 ningún caso ocasionado directamente por la mordedura de un vampiro. Con respecto a la rabia canina, su incidencia disminuyó de 29 casos notificados en 1998 a 4 en 2004.

\section{Reporte de caso.}

El objetivo del estudio es presentar los resultados de una investigación clínica, epidemiológica y de laboratorio para diagnosticar un caso sospechoso de rabia humana transmitido probablemente por un murciélago, destacando la importancia de efectuar vigilancia zoonótica y de desarrollar acciones oportunas de prevención y control.

El 14 de Noviembre de 2004 fue admitida una niña de 12 años en el Hospital General O’Horán de la Ciudad de Mérida, referida de la localidad de Tekax, Yucatán, por una historia de dolor en miembro torácico derecho por aparente traumatismo que no había cedido al tratamiento médico, sin más antecedentes de importancia. La afección continuó con limitación funcional de la muñeca y disminución de la fuerza de dicha extremidad superior, la cual fue progresiva, hasta acompañarse de dolor torácico con limitación de la respiración, fiebre, odinofagia, presentando aerofobia e hidrofobia y cambios en la conducta que se hicieron mas evidentes, por lo que se sospechó de una encefalitis por virus rábico. La niña continúo con deterioro general que hizo necesaria la asistencia ventilatoria, con evolución tórpida y datos clínicos de muerte cerebral declarada el 26 de Noviembre. Durante su internamiento se reinterrogó a la niña y a familiares quienes negaron el antecedente importante de mordedura por algún animal doméstico o silvestre. Asimismo, se le detectaron lesiones dérmicas antiguas en el pie derecho en forma de dos puntos de dos centímetros de separación y huellas de rasguños contiguos sin poder determinarse la causa de las mismas. El LCR fue normal. Se le tomaron impronta de córnea y biopsia de cuero cabelludo, así como muestras postmortem de tejido de encéfalo para su estudio en el Instituto Nacional de Diagnóstico y Referencia Epidemiológicos (InDRE) de la Secretaría de Salud de México.

El caso fue reportado inmediatamente a los Servicios de Salud de Yucatán, trasladándose personal a la localidad de Tekax, una población menor a 50 mil habitantes, dedicada principalmente a la agricultura de autoconsumo y a la ganadería a baja escala, con un Centro de Salud, sin registrar casos de rabia canina y con una cobertura del 94.49\% de vacunación antirrábica canina y felina (3,720 dosis aplicadas, incluyendo a 4 de mascotas de la familia afectada). Se vacunaron a los convivientes del caso y a 1,200 perros y gatos. El personal de salud y agropecuario inspeccionó la zona, reportando condiciones precarias en la vivienda de la niña, localizando contiguamente una cueva artificial abandonada para la extracción de caliza, habitada por murciélagos hematófagos de las especies Desmodus rotundus y Diphila brasiliensis y otros frutivoros e insectívoros, algunos de los cuales aparentemente se alimentaban de aves de patio de dicha vivienda, por lo que se decidió cerrar dicha cueva.

El InDRE posteriormente reportó positivas a rabia, por la técnica de IFD (Inmunofluorescencia Directa), la impronta de córnea y la biopsia de cuero cabelludo. Las muestras de encéfalo, fueron reportadas positivas a la variante antigénica viral V5 de murciélago hematófago, mediante la caracterización del virus rábico por la técnica de anticuerpos monoclonales.

En el seguimiento efectuado a la población de la localidad afectada hasta el 2005 no se reportaron más casos de rabia, tanto humana como canina.

\section{DISCUSIÓN.}

En América Latina como en México la incidencia de casos de rabia humana transmitida por perro se encuentra en franco descenso. Sin embargo, la transmitida por murciélago ha tenido un repunte importante, principalmente en países de América del Sur donde los brotes han 


\section{S Gómez-Carro, ML Ortiz-Alcaraz, E Jiménez-Ríos, S De Los Santos-Briones, E Marín-Pech.}

afectado a numerosas personas al mismo tiempo. Esta problemática no es nueva, pues Brasil y Perú ya han reportado brotes en la región del Amazonas, en áreas donde la población vive en condiciones precarias que facilitan las agresiones por quirópteros, como consecuencia de modos productivos que modifican el hábitat local de las especies silvestres (desmontes, minería, desplazamiento local del ganado). En esas situaciones, las agresiones reportadas siempre fueron nocturnas, con el $62.9 \%$ de las mordeduras en los pies, el $2.9 \%$ en la cabeza y $22.9 \%$ en otros lugares del cuerpo (5).

En México, la Secretaria de Salud ha informado que los casos transmitidos por vampiro han ocurrido en poblaciones rurales en condiciones de vida de pobreza extrema con viviendas de condiciones precarias y en convivencia con animales domésticos.

En Yucatán, el caso sospechoso se presentó en forma aislada, sin que existiera el importante antecedente de agresión por un animal, el cual evoluciono con datos clínicos sugerentes de una encefalitis por virus rábico, planteando la posibilidad de una agresión inadvertida, situación que desencadenó la investigación epidemiológica y de laboratorio, así como de acciones de prevención y control en la localidad afectada.

En el caso se logró el consentimiento informado de los padres para obtener muestras postmortem de encéfalo, para la caracterización antigénica y genética del virus rábico en el InDRE (mediante la técnica de anticuerpos monoclonales y el estudio del ARN viral). Con esta acción de vigilancia epidemiológica, apoyada en el laboratorio, se ha logrado conocer que el murciélago hematófago, de la especie Desmodus rotundus (por las variantes AgV3 y AgV5 de vampiro detectadas en los casos humanos de 2001 y 2004), predomina en el mantenimiento del ciclo silvestre de la rabia en la entidad.

En la localidad afectada la participación de personal agropecuario permitió identificar las especies de murciélagos que habitaban la cueva abandonada y decidir su cierre. Decisión que se tomó por el alto riesgo que implicaba la ubicación del nicho de murciélagos dentro del núcleo poblacional. Si bien las especies no hematófagas, que se encontraban en la cueva no son agresoras, sí pueden actuar como fuente de infección accidental en los seres humanos (7). Por ello debe promoverse la vigilancia zoonótica, mediante la notificación de nichos de murciélagos en localidades rurales marginadas. Sin embargo, hay que difundir la función benéfica de los murciélagos en el equilibrio de los ecosistemas, a fin de evitar su eliminación indiscriminada. Puesto que su función depredadora de insectos nocturnos incluye las plagas que causan a los granjeros grandes pérdidas económicas cada año. Asimismo, porque desempeñan una función de polinización y dispersión de semillas que es fundamental para garantizar la supervivencia de las selvas tropicales. Desafortunadamente, se ha informado que muchas colonias locales de murciélagos han sido destruidas y muchas especies corren peligro de extinción (8-10).

\section{CONCLUSIONES.}

La rabia humana transmitida por perro se encuentra bajo control epidemiológico en el estado de Yucatán.

Por los resultados del estudio epidemiológico y de laboratorio presentados, se puede sustentar que el caso estudiado presentó una agresión inadvertida por murciélago hematófago.

Las acciones preventivas y de control realizadas en la localidad afectada fueron efectivas, en tanto que no se presentaron otros casos de rabia humana transmitida por murciélagos.

En Yucatán el murciélago hematófago de la especie Desmodus rotundus, predomina en el mantenimiento del ciclo silvestre de la rabia, de acuerdo a las caracterización del virus rábico efectuada por el InDRE en los últimos dos casos de rabia humana.

Es importante continuar con la coordinación entre el personal de salud y agropecuario para atender posibles focos rábicos.

\section{Revista Biomédica}




\section{Rabia humana transmitida por murciélago hematófago.}

Establecer pláticas a la comunidad para difundir los factores de riesgo de la rabia transmitida por murciélago y promover la notificación de nichos de murciélagos cercanos a las poblaciones rurales y urbanas marginales.

\section{REFERENCIAS.}

1.- Secretaría de Salud. Programa de Acción: Rabia. México: Subsecretaría de Prevención y Protección de la Salud; 2001. p. 9.

2.- Briggs D, Bourhy H, Cleaveland S, Cliquet F, et al. Expert Consultation on Rabies; WHO; 2005;931: 1-121.

3.- Schneider MV, Belotto A, Ade MP, Leanes LF, Correa E, Tamayo H, et al. Situación epidemiológica de la rabia humana en América Latina en 2004. Boletín Epidemiológico de la OPS 2005; 26 (1):2.16.

4.- Organización Panamericana de la Salud. Área de Prevención y Control de Enfermedades. Unidad de Salud Pública Veterinaria. Eliminación de la rabia humana transmitida por perros en América Latina: Análisis de la situación, año 2004. Washington, D.C.; 2005. 48:49-68.

5.- Schneider MV, Santos-Burgoa C. Algunas consideraciones sobre la rabia humana transmitida por murciélago. Salud Pública Mex 1995; 37:354-62.

6.- Monoclonal antibodies for rabies virus characterization and epidemiological surveillance in Latin America and the Caribean. Rev Panam Salud Publica (on line). Sept. 2000; vol. 8 no. 3 (cited 10 march 2006), p. 214-217. available from World Wide Web: http://www.scielosp.org/ scielo.php?script=sci_arttext\&pid=S1020-49892000000800 016\&Ing=en\&nrm=iso.ISSN 10204989.

7.- Baer GM, Linhart SB, Melvin KA, Acha PN, Allen R, Cabasso VJ, et al. The natural history of rabies. En: Baer MG, editors. The Natural History of Rabies. 2a ed. Boca Raton: Academic Press 1975; vol. II: 229-32.
8.- Losa-Rubio E, Labrandero E, De Paz-Villafuén O. Captura de vampiros (Desmodus rotundus) en cuevas y en corral, y su manejo en cautiverio. En: memorias del V Congreso Nacional de Espeleológica. José Antonio Paz Tenorio ed. Mexico: diciembre 1 de 2000 No. 51 http: //www.montanismo.org.mx/articulos.php?id_sec=6\&id_ art=687\&ik_ejemplar= (2006)

9.- Acha PN, Cifres B. Zoonosis y enfermedades transmisibles comunes al hombre y a los animales. 2da. Ed. Washington: Organización Panamericana de la Salud, 1986; p. 989. Publicación científica No. 503.

10.- FAO Regional Animal Production and Health Officer for Latin America and the Caribbean, Santiago, Chile. Control of bovine paralytic rabies in Latin America and the Caribbean. 2004 Dic. (Cited 2005 Dic 9). Available from: VRL http://www.fao.org/ag/aga/agap/feedback/waqr/v0600b/ v0600b0a.htm. 